\title{
AS RÁDIOS COMUNITÁRIAS \\ NAS CAMPANHAS ELEITORAIS: EXERCÍCIO DA CIDADANIA OU INSTRUMENTALIZAÇÃO $(1998-2000)^{1}$
}

\author{
Márcia Vidal Nunes
}

\section{RESUMO}

O principal objetivo deste trabalho é tentar compreender como se deu o processo de instrumentalização elou do exercício da cidadania nas rádios comunitárias durante as campanhas eleitorais de 1998 e 2000, nas emissoras vinculadas aos chefes políticos locais, nas cidades de Fortaleza, Sobral e Juazeiro, no estado do Ceará. Da mesma forma, o artigo visa a compreender o fenômeno da "espetacularização" da política, as diferentes técnicas jornalísticas e publicitárias utilizadas para a projeção desses políticos profissionais do rádio, além de aprofundar o entendimento do sentido de apropriação da vivência comunitária, percebendo como os chefes locais captam e reelaboram as diferentes estratégias de organização populares. Inicialmente, apresentamos um panorama da evolução das rádios comunitárias no Brasil e no mundo, relacionando-as ao desenvolvimento dos movimentos sociais. Depois, mostramos como a ampliação do exercício da cidadania relaciona-se às experiências midiáticas vividas por membros desses movimentos sociais, destacando seu envolvimento nas rádios comunitárias. Na terceira seção do artigo, identificamos o processo de instrumentalização das rádios comunitárias durante as campanhas eleitorais.

PALAVRAS-CHAVE: rádios comunitárias; eleições; cidadania; mídia.

\section{INTRODUÇÃO}

Vivemos um momento de redefinição da esfera pública social. A lógica argumentativa e a racionalidade que permeavam o discurso em que as questões coletivas eram discutidas e decididas vêm cedendo lugar, paulatinamente, à mídia. É o que Gomes (1998) identifica como a "midiatização da esfera pública", que tem impacto decisivo nas formas de vivência da cidadania e nas práticas comunitárias e sociais a ela associadas.

Para Canclini (1997, p. 247-248), é no contexto da apropriação da cena pública pelos meios eletrônicos de comunicação - que se converteram nos principais formadores do imaginário coletivoque estão presentes os cenários de consumo em que se forma o que poderíamos chamar de "bases estéticas da cidadania".

1 Síntese dos capítulos quarto e quinto do Relatório técnico-científico final do Pós-Doutorado Rádios comunitárias: exercício da cidadania ou instrumentalização nos processos eleitorais de 1998 e 2000?, apresentado no Departamento de Relações Públicas, Turismo e Propaganda da Escola de Comunicações e Artes da Universidade de São Paulo, em junho de 2002.
As rádios comunitárias propõem um exercício da cidadania que implica uma inserção política concreta. E como se constrói o exercício da cidadania por meio das práticas coletivas nas rádios comunitárias durante as campanhas eleitorais? É possível gestar outras formas de lidar com os meios de comunicação durante as campanhas eleitorais, tornando-os instrumentos que viabilizem a participação de segmentos sociais mais amplos nos debates pertinentes à esfera pública política? Ou a manipulação e a instrumentalização seriam os caminhos trilhados pela maioria dessas rádios que se dizem comunitárias, utilizando o rótulo coletivo apenas para disfarçar mais uma forma de apropriação do espaço público pelos interesses privados?

O principal objetivo deste trabalho é, justamente, tentar compreender como se deu o processo de instrumentalização e/ou do exercício da cidadania nas rádios comunitárias durante as campanhas eleitorais de 1998 e 2000 , nas emissoras vinculadas aos chefes políticos locais, nas cidades de Fortaleza, capital do estado do Ceará, e Sobral, e Juazeiro do Norte, os principais núcleos de rádios comunitárias do interior cearense.

Rev. Sociol. Polít., Curitiba, 22, p. 59-76, jun. 2004 
Outra meta deste artigo é compreender o fenômeno da "espetacularização" da política, as diferentes técnicas jornalísticas e publicitárias utilizadas para a projeção desses políticos-profissionais, "donos" do poder local nesses municípios, além de aprofundar o entendimento do sentido de apropriação da vivência comunitária, percebendo como os chefes locais captam e reelaboram as diferentes estratégias de organização populares, neutralizando-lhes as novas possibilidades que poderiam advir de posturas diferenciadas no plano político por meio da efetiva participação de segmentos sociais excluídos de quaisquer tipos de ações coletivas tradicionais.

Inicialmente, apresentamos um panorama da evolução das rádios comunitárias no Brasil e no mundo, relacionando-as ao desenvolvimento dos movimentos sociais. Depois, mostramos como a ampliação do exercício da cidadania relaciona-se às experiências midiáticas vividas por membros desses movimentos sociais, destacando seu envolvimento nas rádios comunitárias. A comunicação comunitária ajuda a fortalecer os movimentos sociais e a consolidar a organização social. $\mathrm{Na}$ terceira seção do artigo, identificamos o processo de instrumentalização das rádios comunitárias durante as campanhas eleitorais.

A realização da pesquisa implicou o acompanhamento da trajetória de alguns políticos proprietários de emissoras comunitárias nas cidades de Fortaleza, Juazeiro do Norte e Sobral, no Ceará, além da gravação e da análise da programação das emissoras estudadas durante o período de uma semana, nas campanhas eleitorais de 1998 e 2000. A idéia era verificar como a publicidade desses políticos foi trabalhada na programação normal da emissora durante a campanha eleitoral.

II. O EXERCÍCIO DA CIDADANIA FACE À REDEFINIÇÃODA ESFERA PÚBLICA SOCI$\mathrm{AL}$

Gomes (1998,p. 163-164) ressalta a decadência da esfera pública moderna, com a diluição dos contornos das esferas pública, privada e íntima, e identifica a perda das três características básicas da esfera pública - a acessibilidade, a discursividade e a racionalidade -, sem falar na degeneração do seu resultado mais essencial, a opinião pública. É justamente a vinculação da esfera pública aos mass media e à mass culture, sua submissão a eles, o fenômeno que configura da maneira mais evidente a degeneração da esfera pública moderna.

Nesse contexto, o exercício da cidadania tornase cada vez mais complexo, já que o público, como tal, é substituído pelas negociações entre organizações e entre partidos, que são as formas por que os interesses privados ganham configuração política (ibidem). Essa participação do público de maneira esporádica e plebiscitária redimensiona as formas de participação popular nas grandes decisões da esfera pública. As posições de pretensões ainda têm que ser mediadas discursivamente, mas não no interior da esfera pública e sim para e diante da esfera pública.

O exercício da cidadania na esfera pública contemporânea assume parâmetros bem diferenciados. Segundo Barbalet (1989, p. 11-12), a cidadania encerra manifestamente uma dimensão política, mas a prática mostra que isso não é suficiente para que ela seja compreendida. O problema está em quem pode exercê-la e em que termos. A questão está, de um lado, na cidadania como direito e, de outro, na incapacitação política dos cidadãos, em razão do grau de domínio dos recursos sociais e de acesso a eles. Por exemplo, da ágora grega não participavam escravos, mulheres e metecos (estrangeiros). No Brasil, a mulher e os analfabetos só adquiriram o direito de votar em 1934 e 1988, respectivamente. Assim, dependendo do período histórico e do país ou lugar, só uma parcela da população pode exercer plenamente a cidadania.

O processo de consumo de bens simbólicos que caracterizaria a vivência de novas formas do exercício da cidadania (CANCLINI, 1997) é essencial para compreender-se a relação que se estabelece entre as comunidades e as rádios comunitárias aí instaladas, que realmente refletem a pluralidade de interesses e de opções no interior de um determinado grupo. Nesse caso, o consumo dos bens simbólicos configurados na programação da emissora é assimilado, reelaborado e devolvido à própria comunidade por meio da reflexão permanente sobre os produtos radiofônicos, que são incessantemente "reconstruídos", colocando-se, assim, em sintonia contínua com os ouvintes da emissora comunitária que integram uma espécie de comunidade virtual, unida por uma linguagem única permeada por interesses coletivos múltiplos.

A noção de cidadania ligada ao consumo leva também à redefinição do conceito de "comunidade". Para Canclini, a história recente da América Latina sugere que, se ainda existe algo como um 
desejo de comunidade, ele relaciona-se cada vez menos a entidades macrossociais, como a nação ou a classe, dirigindo-se, em troca, a grupos religiosos, conglomerados esportivos, solidariedades geracionais e círculos de consumidores de comunicação de massa. Um traço comum a essas comunidades atomizadas é que elas organizam-se mais em torno de consumos simbólicos que em relação a processos produtivos: "É difícil imaginar, por isso, como poderiam contribuir para reanimar a economia. Só em caso de extrema necessidade ressurgem solidariedades econômicas: greves, ondas populares, cooperação nas situações de catástrofe. As sociedades civis aparecem cada vez menos como comunidades nacionais, atendidas como unidades territoriais, lingüísticas e políticas; manifestam-se, principalmente, como comunidades hermenêuticas de consumidores, ou melhor, como conjuntos de pessoas que compartilham gostos e pactos de leitura em relação a certos bens (gastronômicos, desportivos, musicais), que lhes fornecem identidades comuns" (idem, p. 261).

\section{II.1. Rádios comunitárias e práticas políticas no Brasil}

Herdeiras das experiências das rádios livres na Europa e das experiências do Movimento de Educação de Base (MEB) e das radiadoras populares no Brasil, as rádios comunitárias mesclam-se aos movimentos sociais e comunitários. Relacionam-se, assim, com as instâncias políticas como o Estado, sendo alvo de reivindicações e embates dos movimentos sociais e do setor econômico, à medida que concorrem com as rádios comerciais e as instâncias de solidariedade e de circulação dos laços sociais que animam um segmento, ainda que restritamente.

Nahra (1988, p. 110-111) afirma que se pode considerar as rádios comunitárias como rádios livres, especialmente se atentarmos para o fato de que propiciam um contato mais estreito, próximo, íntimo, entre ouvintes e pessoal da emissora, permitindo também a participação direta dos vizinhos nos programas transmitidos. No entanto, se tomadas em conjunto, as rádios livres não são apenas ou principalmente comunitárias. Há casos em que operam em função do cotidiano de um bairro, mas há outros em que aglutinam grupos cuja identidade é construída e expressada a partir de afinidades étnicas, políticas, religiosas culturais etc.

Assim, é necessário definir o que entendemos pela expressão "rádio comunitária". São comunitá- rias as rádios que asseguram a participação plural de amplos segmentos sociais de todos os matizes que compõem uma comunidade, entendida como grupo social, agregado por interesses, vivências e/ou não de um espaço geográfico comum ${ }^{2}$, que participam de maneira organizada e decidem coletivamente os caminhos a serem trilhados pelo grupo, tendo voz ativa nos diferentes canais de participação necessários à estruturação da emissora, tais como vivências políticas, elaboração da programação e assim por diante.

Para Peruzzo (1998, p. 257-258), uma rádio comunitária, para ser assim caracterizada, mais que se circunscrever a uma localidade e falar das suas coisas, não pode ter fins lucrativos, ao mesmo tempo em que deve ter programação comunitária e gestão coletiva, ser interativa, valorizar a cultura local e ter compromisso com a cidadania e a democratização da comunicação.

A origem das rádios comunitárias, no Brasil, relaciona-se às experiências de alto-falantes, utilizadas como "rádios do povo" não só aqui como em outros países da América Latina. Uma das experiências mais conhecidas é a da Vila El Salvador, em Lima (Peru). Em uma comunidade de 200 mil habitantes, estabelecida a partir de um assentamento, o sistema de alto-falantes ajudava ativamente na mobilização e na educação populares. Em 1993. o Centro de Comunicação Popular local, existente desde 1974, já dispunha de uma emissora de rádio e de um canal de televisão. Essa experiência inspirou a implantação de sistemas de alto-falantes na zona Leste de São Paulo. Tudo começou em 1983, com o PROCONEL - Projeto de Comunicação Não-Escrita da Zona Leste II -, que, em 1985, daria origem ao CEMI - Centro de Comunicação e Educação Popular-, dentro do qual, em 1987, constituiu-se uma coordenação das chamadas Rádios do Povo (idem, p. 160-161) ${ }^{3}$.

Outra experiência significativa de sistemas de alto-falantes durante os anos 1980 foi a Rádio Popular de São Pedro, sistema de alto-falantes instalado no bairro de São Pedro I, em Vitória (Espí-

\footnotetext{
2 Com o advento da internete, os conceitos de "identidade" e "comunidade" passam contemporaneamente por redefinições.

3 O pioneirismo coube à Rádio do Povo de Vila Nossa Senhora Aparecida, que foi ao ar em 26.abr.1984. A partir de então, desencadeou-se todo um processo que levou ao número de 42 unidades já em 1988 (PERUZZO, 1998, p. 161).
} 
rito Santo), em 1985, que se transformaria na Rádio Popular de São Pedro em 2 de agosto de 1986, quando seus transmissores entraram no ar pela primeira vez (idem, p. 165) ${ }^{4}$.

Em 1987, as experiências com alto-falantes expandiram-se em Fortaleza, com a implementação de um projeto de rádios comunitárias pela Prefeitura ${ }^{5}$. O sistema de alto-falantes do Jardim Iracema já funcionava desde 1982. Em 1988, seis experiências pioneiras entraram em funcionamento nas regiões de Parangaba (Serrinha), Antônio Bezerra (Conjunto São Francisco), Barra do Ceará (Buraco do Céu), Mucuripe (Jardim Nova Esperança), Mondubim (Acarape) e Messejana (Lagoa Redonda). Assim, no início da década de 1990 foram contabilizadas um total de vinte rádios comunitárias em funcionamento na periferia de Fortaleza (COGO, 1998, p. 120).

Cogo (idem, p. 124) registra também as experiências de rádios populares ou comunitárias em Recife, com a inauguração, em 1984, da primeira emissora de alto-falantes, a Rádio Sabiá, no bairro de Guabiraba, em Casa Amarela.

Surgiu em Vitória, no Espírito Santo, a primeira rádio livre brasileira em outubro de 1970, sendo fechada em fevereiro de 1971, no auge da ditadura militar, sob o governo de Emílio Garrastazu Médici (NUNES, 1995, p. 104). A rádio Paranóica foi criada por dois irmãos adolescentes transmitindo diariamente em FM. A programação era basicamente musical e a experiência durou um mês (NAHRA,1988, p. 165). Depois surgiria a Rádio Spectro, de Sorocaba (São Paulo), em 1976. A imprensa informou que essa cidade chegou a ter mais de quarenta emissoras desse tipo no início da década de 1980. Outra pioneira seria, em 1978, a Rádio Globo de Criciúma (Santa Catarina) (PERUZZO, 1998, p. 243).

Nos anos 1980 surgiram em São Paulo inúmeras rádios livres. Em 1985, além da Xilik e da Rádio Totó Ternura, havia mais cinco no ar (NAHRA, 1988, p. 173-174): a rádio Patrulha, de Ermelino Matarazzo, na zona Leste - emissora da comunidade voltada para os problemas do bairro que se iniciou a partir

\footnotetext{
4 A rádio fechou definitivamente em 1994.

5 Na ocasião assumira a Prefeitura a sociólogia Maria Luiza Fontenelle, primeira Prefeita brasileira eleita pelo Partido dos Trabalhadores (PT) em uma capital brasileira (1986).
}

da utilização do sistema de alto-falantes com a programação elaborada pelos próprios moradores do bairro -; a Bruaca, na zona Sul; a Ilapso, na zona Oeste; a Neblina, no município de Guarulhos, e a rádio Tereza.

Destaque merece a Rádio Livre Paulicéia, de Piracicaba (SP), uma das experiências mais significativas de rádio livre comunitária, que, com dez watts de potência, funcionou de 14 de julho de 1990 a 3 de abril de 1992. Sem fins lucrativos, de propriedade dos moradores do bairro de igual nome e ligada ao centro comunitário local, ela surgiu da necessidade de mobilizar a população para um mutirão da Prefeitura, mas cerca de quinze dias depois tomou rumo próprio (PERUZZO, 1998, p. 251).

No Rio de Janeiro, a primeira rádio livre foi Frívola City, surgida em 1986 (NAHRA, 1986, p. 177-178). Frívola City foi uma das primeiras rádios livres a engajar-se na campanha política para as eleições de 1986, apoiando a candidatura de Fernando Gabeira ao governo do estado, pela coligação Partido Verde (PV)-Partido dos Trabalhadores (PT), ampliando o espaço eleitoral dos pequenos partidos, muito reduzido nas emissoras comerciais $^{6}$.

A rádio Reversão surgiu em São Paulo e foi fechada em 09 de abril de 1991, tendo seus equipamentos apreendidos pela Polícia Federal e por agentes do Departamento Nacional de Fiscalização das Comunicações, antigo DENTEL, tornouse uma referência cultural na comunidade onde surgiu, com uma produção rica e criativa, estimulando o ouvinte a criar e a participar das emissões (NUNES, 1995, p. 12).

Segundo Leo Tomaz, antigo dono da rádio Reversão, "as rádios livres servem como canais de expressão do descontentamento e como tentativa de sublevar essa 'identidade traçada' pela mídia. 'Fazemos rádio livre para democratizar os meios de comunicação, democratizar os mitos, a indústria da produção cultural e os meios de divulgação cultural"' (Tomaz apud NUNES, 1995, p. 12).

$\mathrm{O}$ grupo que dirigia a rádio estimulava também

6 Em Belo Horizonte (NAHRA, 1988, p. 177-178), Fernando Cabral, candidato do PT ao governo do estado de Minas Gerais, contou com o apoio da rádio livre (TEM CABRAL NO SEU DIAL, 1987, p. 103). 
a vinda de políticos à emissora, para debater com os ouvintes presentes, como Fernando Gabeira, então candidato à Presidência da República em 1989, pelo Partido Verde, e o vice-Prefeito de São Paulo, à época Luiz Eduardo Greenhalg (idem, p. 15).

A Rádio Novos Rumos, em Queimados, surgiu na Baixada Fluminense, em dezembro de 1990, e foi fechada em 15 de maio de 1991; foi uma das experiências de rádio comunitária mais importantes do Brasil. Os programas geralmente eram feitos ao vivo, com exceção dos religiosos, produzidos pelas próprias igrejas. Na rádio encontravam espaço os batistas, os pentecostais, os católicos e os católicos carismáticos. Um dos resultados mais impressionantes da Novos Rumos foi a diminuição dos índices de violência na comunidade, durante os três meses em que a rádio ficou no ar. Segundo Sebastião Correa dos Santos, radialista e um dos idealizadores da rádio, a emissora veiculava um programa policial, apresentado por um ex-policial militar que tinha ligações com o delegado local: "Ele agia como um defensor público e ameaçava os criminosos. A violência diminuiu bastante no período da rádio. [...] É uma briga entre o mar e o rochedo. É incrível que se impeça que essas experiências sejam legalizadas. A gente quer ver o povo falar, fazer valer a sua cultura. Nós também temos capacidade de elaborar nossos próprios programas, mas não basta ter canais nas mãos do povo. É preciso dar condições para que o povo faça desses canais um exercício constante de cidadania" (idem, p. 19).

A rádio Favela FM 104,5 é uma das mais importantes experiências de rádio comunitária atualmente em operação no país (BREGUÊS, 2001). A rádio fica na favela Nossa Senhora de Fátima, que integra outras favelas do bairro Serra, de Belo Horizonte, como mostra uma pesquisa feita por Sebastião Geraldo Breguéz. O autor acompanhou de perto o trabalho da rádio por quase dois meses, fez entrevistas com a equipe da emissora, com moradores da favela e ouvintes de várias regiões de Belo Horizonte.

A Favela FM já ganhou dois prêmios da Organização das Nações Unidas (ONU), que reconheceu seu trabalho social contra as drogas, além de medalhas e comendas estaduais e municipais. Em agosto de 2000 foi a única rádio brasileira que participou do Congresso Mundial de Rádios Comunitárias em Milão (Itália). O Sindicato de Jorna- listas da Alemanha considera a experiência da Favela FM como uma revolução nos meios de comunicação do Terceiro Mundo. Durante o período das eleições 2000, Breguês presenciou os candidatos desfilarem bem vestidos e em carros importados nas estreitas ruas da favela Nossa Senhora de Fátima, à busca de votos. Abraçaram crianças desnutridas e cheia de vermes (na expressão do fundador da emissora, Misael Avelino dos Santos, "crianças com aquário na barriga"), deram entrevistas na Favela FM 104,5, pedindo votos e prometendo ajudar a população.

A Favela FM é uma emissora criada por favelados, em 1981, com a ajuda da Igreja Católica e da associação de moradores, com o objetivo de atender às necessidades da localidade, principalmente aos problemas de segurança e de drogas. Ela situa-se em uma região responsável por cerca de $25 \%$ dos homicídios que acontecem em Belo Horizonte e pela maior taxa de crescimento demográfico do município, com grande número de crianças. O sucesso foi tão grande que a rádio transformou-se na terceira maior audiência de Belo Horizonte. Com uma programação musical variada, um jornalismo realista e com denúncias, a Favela FM conquistou a confiança dos ouvintes. Breguéz afirma que também foram eficazes os programas anti-drogas e pró-estudo - pois eles faziam a distribuição gratuita de material escolar (livros, cadernos e lápis) para os estudantes pobres das favelas (ibidem).

Esse trabalho, porém, não foi coroado apenas de conquistas, mas também de perdas. Da turma inicial, poucos restaram. Muitos envolveram-se profundamente com o tráfico de drogas, outros foram assassinados em brigas, alguns mortos pela polícia ou simplesmente desapareceram. Hoje, o trabalho continua e há apoio de sindicatos, sociedades filantrópicas, empresas e particulares (ibidem).

Houve muita repressão ao funcionamento da rádio, mas, desde 1995, o líder fundador da emissora, Misael Avelino dos Santos, resolveu parar de fugir e ter uma sede fixa. Diz ele: "A nossa rádio é diferente das outras rádios 'piratas', pois faz um trabalho social, cultural e educacional. Nós não queremos ganhar dinheiro, não somos empresários, só queremos ajudar a população pobre e marginalizada dos morros. Portanto, a nossa rádio tem uma vocação social, é rádio comunitária por excelência. Trabalhamos pela dignidade e pelo 
reconhecimento da cidadania dos moradores dos morros. Lutamos contra o tráfico de drogas. Não podem prender-nos como ladrões ou traficantes". A partir daí e com o crescimento da audiência e do reconhecimento do trabalho deles, a repressão tem diminuído (ibidem).

No Ceará, uma das experiências mais importantes de comunicação educativa é a rádio Mandacaru FM 98,5, situada no bairro Ellery, em Fortaleza, com gestão coletiva e programação plural, que é feita totalmente pela população do bairro. Na rádio, a vivência cultural por meio da música é o caminho que atrai o povo a exercer sua cidadania, participando de movimentos sociais e políticos (OLIVEIRA, 2002, p. 135): "Fica evidente que a proposta sócio-educativa da Mandacaru definese pela promoção do lazer e da dinâmica musical que a emissora prioriza. Na verdade, esse estilo, mais do que uma definição $a$ priori, é o resultado da abertura que a emissora vem dando aos diversos grupos culturais presentes na rádio. Portanto, uma emissora estruturada pela Associação Comunitária do Bairro Ellery, entidade tradicionalmente fundamentada em uma filosofia polarizadora que se apóia em atividades como debates, reuniões, mutirões, passeatas e mobilizações de cunho político, distanciadas do vínculo com o lazer, passou a desenvolver por meio da rádio comunitária Mandacaru FM uma aproximação mais sólida com uma proposta comunicativa que destacou um processo educativo mais amplo do realizado anteriormente. Isso ocorre porque, além de utilizar elementos de mobilização política e de priorizar as assembléias, reuniões, cursos e debates como estratégias de mobilização e educação política, passou-se a destacar por meio da música, da produção artística e do lazer uma proposta educativa mais sedutora".

Outra experiência cearense, internacionalmente conhecida, é da Rádio Comunitária Casa Grande FM, que fica no município de Nova Olinda, na região Sul do estado, a $600 \mathrm{~km}$ de Fortaleza. Tanto Oliveira (idem) quanto Acioli (2002) consideram Casa Grande FM uma experiência de "educomunicação". A rádio integra, na verdade, uma amplo projeto de comunicação educativa, em que as crianças começam a exercer sua cidadania a partir do reforço à identidade cultural local e de vivências coletivas que ampliam seus horizontes, envolvendo produção em televisão, teatro, grupo musical, editora e outras atividades culturais realizadas por crianças e adolescentes, que são também responsáveis pela gestão do processo, sob a supervisão de Alemberg Quindins e Rosiane Limaverde, músicos e animadores culturais em Nova Olinda. "[...] A Fundação Casa Grande pode ser definida como um projeto de educomunicação, por possuir as características de educação para os meios de comunicação; da autogestão, ou gestão de um ecossistema educomunicativo; da intermediação tecnológica no processo educativo e da reflexão epistemológica, presente nesse trabalho.

Esse projeto cabe nas definições de educação de Paulo Freire, na medida em que os meninos adquirem autonomia e tornam-se capazes de refletir sobre sua própria existência, definindo o caminho que desejam seguir.

Mais do que isso, eles adquirem a liberdade de soltar a enxada e escolherem um futuro de acordo com as suas inclinações, conscientes de que são parte de um todo, mas sem perder a forte ligação com a memória do lugar onde vivem" (idem, p. 55).

Com a mobilização e o crescimento das rádios comunitárias no Brasil, o que mudou foi que, na década de 1990, as rádios livres, posteriormente chamadas de rádios comunitárias, passaram a ser uma iniciativa não mais de jovens amantes da tecnologia, restrita ao eixo Sul e Sudeste do Brasil, mas constituíram-se em experiências existentes por todo o território brasileiro, envolvendo também iniciativas dos movimentos sociais e culturais populares; houve também o aparecimento de emissoras financiadas e promovidas por políticos, comerciantes e religiões evangélicas (idem, p. 51).

No universo das 15000 emissoras FM comunitárias que existem no Brasil atualmente, fica difícil precisar o número de emissoras organizadas por movimentos sociais e culturais populares ${ }^{7}$. É notório que esse número é reduzido em relação às emissoras comunitárias organizadas por políticos e pequenos empresários. A realidade de Fortaleza pode situar melhor essa situação: de cinqüenta emissoras, apenas cinco têm a gestão de grupos

\footnotetext{
7 Em pesquisa realizada por Nunes (1995), com a colaboração do DX-Clube Paulista ,uma associação de rádio-escuta, foram sintonizadas 50 emissoras livres, entre os meses de março de 1994 e fevereiro de 1995 - a maioria localizada na zona Norte da cidade. Dessas emissoras, $44 \%$ tinham caráter religioso-evangélico; $24 \%$ comercial-musical; $24 \%$ cultural e $8 \%$ não foram identificados. Do total, $68 \%$ tinham fins lucrativos, $24 \%$ eram sem fins lucrativos e $8 \%$ não foram identificados
} 
culturais e de organizações populares (idem, p. 52).

Entidades que congregam emissoras clandestinas estimam que cerca de 2000 rádios piratas, em todo o país, estejam hoje sob controle de políticos e que outras 4000 estejam nas mãos de religiosos. No país, operam cerca de $10 \mathrm{mil}$ emissoras $^{8}$ sem concessão. As emissoras controladas por políticos são administradas por testasde-ferro ou por associações (CASTRO, 2000, p. A6) ${ }^{9}$.

A legalização das emissoras comunitárias por meio da Lei n. 9612, aprovada em fevereiro de 1998, com restrição da potência do transmissor, definindo as regras de participação da sociedade civil, vetando a formação de redes, impedindo a utilização de publicidade, praticamente inviabilizou a existência da maior parte das experiências comunitárias, favorecendo, na prática, a sobrevivência das emissoras ligadas a políticos e comerciantes, que são as que estão recebendo as autorizações para funcionamento legalizado em sua maioria. Já existe um novo projeto de lei, cujo objetivo é aprimorar a lei atualmente em vigor, que inviabiliza, na prática, a continuidade de inúmeras experiências.

Atualmente, existem rádios dos mais variados formatos, desde comercial-musicais, comercialevangélicas, comunitário-autogestionárias, de bairro, de universidade, de grupos culturais, anarquistas, de movimentos musicais, de minorias e muitas outras (NUNES, 1995, p. 172): "Em São Paulo, por exemplo, a maioria das intervenções com caráter comercial-musical e comercial-evangélica reproduz a mídia oficial, explorando o rádio com a venda de anúncios, aluguel de horários e divulgação de produtos do mercado organizado de bens culturais.

\footnotetext{
8 Juntas, as rádios comunitárias atingem entre 115 mil e 140 mil ouvintes por minuto na Grande São Paulo, na média diária, das $5 \mathrm{~h}$ às $24 \mathrm{~h}$. No conjunto, ocupam o quarto lugar na classificação das FMs paulistanas.

${ }^{9}$ Em notícia publicada no jornal $O$ Povo (NO CEARÁ, 40 RÁDIOS, 2002, P. 8), de acordo com dados do Ministério das Telecomunicações, entre março de 2000 a dezembro de 2001, foram dadas autorizações, publicadas no Diário Oficial da União, para que 40 rádios comunitárias funcionem no Ceará, de Irauçuba a Chorozinho, de Aracati a Itarema. Depois que as autorizações são publicadas no Diário Oficial, as entidades que receberam a outorga têm até seis meses para colocar as emissoras no ar.
}

Esse formato, na prática, não traz inovação na linguagem e apenas minituariza o sistema de comunicação oficial”.

\section{II.2. Rádios comunitárias e o exercício da cida- dania}

De acordo com o trabalho de Oliveira (2000, p. 11), embora essas possibilidades democráticas ou espaço de embates, reivindicações e denúncias possam ser verificadas na mídia convencional e comercial, os atores sociais, principalmente os movimentos e grupos sociais organizados, também lutam pela constituição de novas formas midiáticas diferentes das características que marcam o modelo comercial hegemônico, propondo a reconfiguração de suas práticas interacionais na esfera pública. A tese principal é da democratização da comunicação que, entre outras coisas, propõe a constituição e ampliação das chamadas mídias comunitárias, cuja concretização já se tornou um fenômeno recente no panorama da comunicação midiática brasileira, por meio de regulamentação em 1998.

Assim, teoricamente, elas devem possibilitar o rompimento com as práticas discursivas que impõem o "silêncio" e a hegemonia de opiniões como é feito comumente na mídia comercial, cuja maioria é declaradamente descompromissada com o interesse coletivo, e indicar novas formas de construção da agenda pública. Isso pode ser possível graças à crescente expansão e implantação de diversificadas experiências levadas a cabo por várias rádios comunitárias que colocam no ar diferentes vozes e questões no cenário público. A tecnologia simples e barata, a delimitação do espaço de transmissão que permite melhor interatividade com a audiência, a organização semiprofissional que permite o trabalho voluntário e sem interesses pecuniários e a desburocratização, que facilita a participação do público na produção, transmissão e recepção das mensagens, são fatores decisivos para realizar tais propósitos. Assim, a opinião dominante difundida na mídia convencional, que busca formar uma espiral de silêncio diante da maioria, pode ser contraposta à prática de muitas emissoras radiofônicas comunitárias, embora não se possa verificar esse resultado em seu conjunto.

$\mathrm{Na}$ sociedade atual, em que a tecnologia e a velocidade colocam-se em evidência nas dinâmicas sociais, faz-se necessário pensar a comunicação que se pode realizar nos meios populares. Mais do que as deficiências, até mesmo estruturais, em áreas como educação, saúde, moradia, trabalho e 
lazer, com que as camadas populares são obrigadas a conviver cotidianamente, a exclusão na produção social de informação e, logo, de comunicação destitui esses grupos do direito de decisão, participação e exercício da cidadania (SPENILLO, 2001, p. 2).

Os novos meios e recursos de comunicação de massa ocupam, nesse contexto, um lugar decisivo. Estratégias de sedução cada vez mais sofisticadas são utilizadas por esses meios, que se transformam em instrumentos de conquista do público por interesses privados. Poderíamos falar de uma esfera pública midiatizada, em que os meios de comunicação assumem o papel de intermediários entre os grupos e seus interesses específicos com o restante da sociedade?

Para Guerra (apud AGUILAR, 1999, p. 93), os meios de comunicação e os jornalistas devem renunciar à tentação de substituir partidos e instituições, ou de serem utilizados como plataformas de grupos de poder para fins antidemocráticos. A missão dos meios de comunicação não é a de pretender substituir as instituições que não funcionam, mas, sim, de contribuir para que elas funcionem e consolidemse.

Razio (apud AGUILAR, 1999, p. 97) afirma que o processo de estrangulamento deliberado da democracia vem levando a uma fragmentação paulatina da sociedade. Com isso, vêm sendo destruídos dois fundamentos decisivos da democracia liberal: o princípio do governo responsável e de um povo democrático com capacidade consensual. O resultado é uma democracia vazia e carente de sentido, como acontece com o conceito de cidadania. O povo desintegra-se com maior força; grupos que não se suportam atacam-se entre si. Vivemos em um mundo de democracias formais, não reais, em que mandam os investidores e os especuladores financeiros, não os governos.

Dirkos (apud AGUILAR, 1999, p. 281) destaca que como resposta a essa progressiva desumanização, produziu-se um peculiar e notório surgimento de pequenos meios - especialmente emissoras radiofônicas de freqüência modulada de baixa potência - que ocupam um espaço deixado vazio e recriam a função essencial da comunicação social - a possibilidade de expressão de seres humanos concretos, dentro de uma sociedade concreta. Esses meios, legitimamente denominados comunitários, constituem o eco dos verdadeiros problemas, frustrações e esperanças de seu povo, localidade ou bairro. Cria-se, assim, um âmbito mais humano dentro do qual se recupera o sentido fundamental da comunicação: servir de vínculo ao intercâmbio de idéias e valores entre os membros da comunidade de que são parte. Por meio delas começam a expressar-se os próprios vizinhos, as instituições intermediárias, culturais, sociais, políticas e esportivas de cada localidade, o que de nenhum modo será possível sem a existência desses meios locais. Sua legitimidade foi comprovada, de outra forma, pela inserção que obtiveram; criados, concretizados e recebidos pelos membros da própria comunidade, que, embora contassem com a possibilidade de escolher uma programação cada vez mais ampla a partir da chegada do satélite, conservaram um espaço privilegiado em suas preferências.

Mohme (apud AGUILAR, 1999, p. 108) trabalha com a concepção de cidadania participativa. Se a informação é poder, então a tarefa dos meios de comunicação democráticos é respeitar o direito à informação do povo em que reside a soberania. No século XX consolidou-se o fato de que não há política sem meios de comunicação e não há meios de comunicação sem política. Para o autor, os meios de comunicação de massa devem contribuir para a democratização da comunicação, com os intermediários entre a cidadania e a classe política canalizando, difundindo, multiplicando ou diminuindo determinadas opiniões. Outorgam e retiram a credibilidade de determinados líderes e formações políticas. Uma segunda tarefa em prol da democratização é permitir a expressão das opiniões do cidadão comum, de maneira que termine o círculo vicioso de opiniões e confirmações ou discrepâncias entre os membros da classe política que termina afastada cada vez mais dos interesses e inquietudes concretos da cidadania. Se a informação somente flui em um só sentido, criamse e reproduzem-se cidadãos passivos que só se contentam em estar informados e não em participar ativamente dos assuntos públicos.

Uma outra tarefa dos meios de comunicação, segundo Mohme (ibidem), é fornecer informação relevante e não só de fatos acessórios que ocorrem cotidianamente. Outra postura dos meios de comunicação é fiscalizar a gestão pública. Finalmente, eles podem contribuir para a democratização da política, comunicando-se com seus diversos atores, dando a conhecer suas posições, suas discrepâncias e coincidências e buscando consen- 
sos em meio aos conflitos - pois sabemos que sua influência entre os cidadãos é enorme.

A forma autogestionária, como se estruturam as rádios comunitárias como projetos pequenos de comunicação, em que se busca descentralizar a informação e exercitar a liberdade de informação, leva ao exercício efetivo da cidadania (NUNES, 1995, p. 199). Ao democratizar a comunicação social, é possível estabelecer novas condições para formarse uma diferença futura em conteúdos - por exemplo, com a formação de uma opinião pública mais próxima da realidade, com o desenvolvimento da consciência crítica e da própria educação.

Para Nunes (ibidem), um processo completo, que desloca a idéia do "mega" e abraça a idéia do pequeno, que inclui liberdade de expressão, informação confiável e produção cultural própria, pode ser, sim, um contraponto - uma alternativa à forma como se organiza a mídia oficial. Os valores já não serão mais aqueles padronizados pelo mercado oficial de bens culturais e sim aqueles que constroem a identidade da comunidade ou do grupo que organiza o processo, favorecendo a subjetividade e a cidadania.

A rádio livre estabelece, assim, novas relações de poder, como ressalta Nunes (idem, p. 212). O que a rádio livre representa para a comunicação social é a geração de novas relações de poder, descentralizado e democratizado. O primeiro passo para isso é admitir que o poder é bom, pode libertar e emancipar. A força que os monopólios possuem, em nível nacional, de influenciar comportamentos ou opiniões públicas pode ser dividida sem ser reduzida sua intensidade, porque será outra e com referências localizadas.

A atuação em rádios comunitárias pelos militantes de movimentos sociais confere-lhes maior segurança e um conhecimento mais detalhado da causa que defendem. A produção de material para ser veiculado ao público gera, além disso, laços de solidariedade mais estreitos entre os participantes do grupo, fortalecendo a coesão interna e deixando mais nítidos os objetivos que o grupo persegue. Assim, o papel das rádios comunitárias transcende a publicidade da causa defendida pelo movimento social junto à sociedade; ele fortalece o movimento social e ajuda a moldá-lo melhor, inclusive ampliando a percepção dos próprios militantes em relação aos objetivos que defendem e a causa que perseguem. É como ouvir o próprio eco e refletir sobre ele.
Além de tudo isso, fazer rádio comunitária é uma forma alternativa de exercer a cidadania e estabelecer laços sociais mais amplos com o conjunto da sociedade. O que começa como um movimento social por meio do uso de meios de comunicação alternativos pode crescer e desembocar em um movimento social de massa. Esses movimentos sociais, muitas vezes, podem transformar-se em movimentos políticos, o que lhes pode conferir uma outra configuração social. Esse processo é diferenciado da instrumentalização eleitoral que alguns partidos políticos fazem da rádio comunitária. Esse é um processo inverso, de cima para baixo, em que a rádio é instrumento de doutrinação e arregimentação, convertendo-se, na melhor das hipóteses, em um mecanismo de fortalecimento de uma organização política dentro da sociedade, quando o grupo político está em sintonia concreta com as reais expectativas coletivas.

\section{INSTRUMENTALIZAÇÃOELEITORALDAS EMISSORAS DE RÁDIO}

\section{III.1. Coronelismo eletrônico: do voto de cabres-} to ao controle midiático

As rádios comunitárias do Ceará proliferam-se cada dia mais, seja em bairros de Fortaleza ou em cidades do interior. Por lei, é proibida sua utilização para fins político-partidários. No entanto, o que se observa é a desobediência da lei e um uso abusivo desses meios para promoção deste ou daquele candidato durante as campanhas eleitorais e, principalmente, no período que antecede ao seu início. Um fator preponderante que permite que isso seja feito é que, em sua maioria, as rádios ditas comunitárias pertencem a políticos.

A primeira fase da pesquisa, realizada durante os anos de 1997 e 1998, abrangeu dois municípios do interior cearense e a capital do Ceará, Fortaleza. Na primeira etapa foram selecionadas as emissoras Rádio Sal da Terra 101,1 (Sobral), Rádio Emoção FM 104,9 (Fortaleza) e Rádio Juazeiro FM 102,5 (Juazeiro do Norte), no ano de 1998. A trajetória de três candidatos (José Linhares, do Partido Progressista Brasileiro (PPB) de Sobral; Gorete Pereira, do Partido da Frente Liberal (PFL) de Fortaleza e José Arnon Bezerra, do Partido da Social-democracia Brasileira (PSDB) de Juazeiro do Norte), proprietários de emissoras denominadas comunitárias, foi acompanhada de perto durante esse período. Em 2000, foram acompanhadas duas emissoras de Fortaleza vinculadas a candidatos que estavam envolvidos no processo eleitoral: Portugal 


\section{FM 97,7 e Mandacaru FM 98,5.}

Há cerca de 300 emissoras denominadas “comunitárias" em todo o Ceará atualmente. A grande maioria dessas emissoras vêm assumindo um papel nitidamente instrumental, quer seja para fins político-partidários, nos períodos que antecedem as campanhas eleitorais e no seu decorrer, quer para fins comerciais, desvirtuandose do seu real papel, que seria a promoção dos interesses comunitários.

Vários políticos profissionais no estado, que querem eleger-se pela primeira vez ou que tentam a reeleição, ou mesmo empresários montaram verdadeiras redes de rádios comunitárias, com o objetivo de utilizá-las durante o período eleitoral Logo no início do seu movimento de expansão, a rádio comunitária distinguia-se da rádio comercial convencional porque ainda não era regulamentada e funcionava sem a concessão do poder público, que só aprovou sua regulamentação em junho de 1998.

Muitas rádios são montadas por políticos para serem utilizadas durante a campanha eleitoral e, depois, revendidas ${ }^{10}$ para comerciantes locais. Com um custo relativamente baixo, em torno de $\mathrm{R} \$ 10000,00$ a $\mathrm{R} \$ 15000,00$, a rádio apresentada à população como supostamente "comunitária" tem programação predominantemente comercial (com grande quantidade de programas musicais), muita publicidade vendida a um preço bem mais baixo do que as emissoras comerciais costumam cobrar e divulgação sistemática do candidato ou político que a patrocinou.

Há, também, o caso das emissoras comunitárias "mistas": elas não são totalmente instrumentalizadas pelos políticos, contando com certa participação popular. Algumas emissoras são montadas por políticos e, depois, entregues à comunidade, que passa a gerenciá-las, contando com o apoio do chefe político. No Pecém, no Ceará, uma rádio montada por Léo Alcântara entregou a administração da rádio a um representante

10 Um radialista de Sobral, trabalhador em uma emissora comercial e que não quis identificar-se, revelou que um candidato a Vereador conhecido por Paulão, do PSDB, montou pelo menos três rádios e vendeu-as (uma delas a um proprietário de um supermercado local). Ele revelou que esse é um excelente negócio. Uma rádio especificamente que custou $\mathrm{R} \$ 15000,00$ ao político teria sido revendida por $\mathrm{R} \$ 45000,00$. comunitário, iniciando uma forma de gestão mista. Em Fortaleza, em 2000, a Deputada Estadual pelo PFL, Gorete Pereira, tentou fechar um acordo com o Conselho Comunitário da Serrinha, entregando a rádio Emoção FM para ser gerida pela comunidade, desde que controlasse $50 \%$. O acordo não saiu e a rádio encontra-se fechada pela Agência Nacional de Telecomunicações (ANATEL).

Procurando reproduzir a programação das emissoras comerciais, apresentando uma composição comunitária artificial, reunindo associações comunitárias forjadas em sua maioria pela ação de cabos eleitorais, essas emissoras indevidamente chamadas de "comunitárias" apropriam-se do espaço comunitário, privatizando a dimensão pública do que seria um espaço coletivo de articulação, de organização e de conscientização políticas das comunidades que não dispõem de instrumentos de comunicação próprios.

O processo de criação dessas rádios pode-se dar de várias maneiras. $\mathrm{O}$ chefe político delega poderes a algum correligionário que "organiza" a rádio "comunitária" nos termos exigidos pela legislação, arregimentando lideranças locais em torno da criação da rádio, cujos equipamentos e manutenção são custeados pelo político e pela publicidade vendida. Nos períodos em que não há campanha eleitoral, a rádio funciona como uma rádio comercial comum, sendo um canal de promoção do político junto à população local. Mas há casos em que a rádio comunitária pertence a um líder político e são concedidos espaços para a participação popular, dando a impressão de que a rádio comunitária é plural, porque conta com a participação de diversos segmentos sociais. Assim, a rádio comunitária tem uma aparência "legítima", mas o controle dela não é da população, porque o chefe político está por trás dela, exercendo sua influência, usando a rádio para autopromover-se, nem que seja de maneira indireta e podendo, a qualquer momento, exercer sua autoridade e "cobrar" da comunidade serviços em troca do "benefício" de coletivização da emissora.

Em sistematização preparada por Dioclécio Luz a partir da leitura do Diário Oficial da União, (Coletivo Petista das Rádios Comunitárias no Congresso Nacional apud BAYMA, 2002), em que se encontram as rádios comunitárias autorizadas pelo Ministério das Comunicações, há a informação de que o total de solicitações ao Ministério das Comunicações até 29.maio.2000 era de 9 521; as 
maiores demandas eram: 1613 em São Paulo; 1525 em Minas Gerais; 398 no Rio de Janeiro; 593 na Bahia etc. A tramitação dos pedidos de autorização das rádios comunitárias no Congresso Nacional sistematizada por Dioclécio Luz e atualizada pela última vez em 21.maio.2002, revela que havia 1275 pedidos de autorização em tramitação. Desse total, já haviam sido outorgadas pelo Congresso 268, o que equivalia a $21 \%$ do que o Ministério das Comunicações autorizou. Portanto, pode ser que algumas ainda não estejam tramitando na Câmara dos Deputados. Depois que o Ministério das Comunicações autoriza, o processo é encaminhado à Presidência da República, que então despacha para o Congresso Nacional.

Em um levantamento realizado por Bayma (2002), para a assessoria técnica do Partido dos Trabalhadores (PT) na Câmara dos Deputados, a partir de cruzamento de dados da ANATEL, do Ministério das Comunicações e do Tribunal Superior Eleitoral, constatou-se que a chamada base aliada do governo Fernando Henrique Cardoso dominava incríveis $73,75 \%$ do total de emissoras de radiodifusão do país. Das 3315 concessões de emissoras de radiodifusão brasileiras atualmente em funcionamento (271 de televisão, 1579 de OM, 64 de OC, 80 OT e 1321 de FM), 37,5\% do total (pouco mais de 1220 ) são exploradas por políticos do PFL; membros do Partido do Movimento Democrático Brasileiro (PMDB) aparecem em segundo lugar: são sócios de $17,5 \%$ das emissoras. Na sequiência estão o PPB, com $12,5 \%$ e o PSDB e o PSB empatados, cada qual com $6,25 \%$. Todos os demais partidos não superam $5 \%$ do total.

Segundo Lima (2001, p. 107-108), levantamento divulgado em 1995 já indicava que 31,12\% das emissoras de rádio e televisão no Brasil eram controladas por políticos e, em alguns estados da Federação, metade ou quase a metade $(40,9 \%)$ das emissoras de rádio estava sob controle de políticos. O mesmo autor revela também que os candidatos que estavam à frente nas pesquisas eleitorais para os pleitos majoritários - governadores e senadores - em pelo menos 13 estados eram políticos vinculados à área de mídia. Isso ocorria em Roraima, Amapá, Ceará, Maranhão, Rio Grande do Norte, Acre, Rondônia, Mato Grosso, São Paulo, Sergipe, Bahia e Alagoas.

O número de parlamentares vinculados à mídia que se elegem para o Congresso Nacional desde a Constituinte de 1988 tem ficado em torno de 23\% (idem, p. 108-109). No Congresso Constituinte $26,1 \%$ eram concessionários de emissoras de rádio e/ou televisão (MOTTER, 1994, p. 98); na Legislatura de 1991-1994, 21,47\% dos deputados federais (LIMA, 1991, p.16) e, na Legislatura de 1995-1998, 21,85\% dos deputados e senadores tinham uma concessão de rádio ou de televisão ou uma combinação das duas (Góis apud LIMA, 1991, p. 43).

Bayma utiliza o termo "coronelismo eletrônico", justificando que a literatura política brasileira tem utilizado o termo "coronelismo" como uma forma peculiar de manifestação do poder privado, com base no compromisso e na troca de proveitos com o poder público. A Ciência Política trata o coronelismo como a relação entre os coronéis locais, líderes das oligarquias regionais, que buscavam tirar proveito do poder público no século XIX e início do século XX. Hoje não há como deixar de associar esse termo aos atuais impérios de comunicação mantidos por chefes políticos oligárquicos, que têm, inclusive, forte influência nacional. O compadrio, a patronagem, o clientelismo e o patrimonialismo ganharam, assim, no Brasil, a companhia dos mais sofisticados meios de extensão do poder da fala até então inventados pelo homem: o rádio e a televisão.

Segundo Bayma (2002), constituindo-se em um dos traços determinantes do atual poder oligárquico nacional, a posse de estações de rádio e de televisão por grupos familiares e pelas elites políticas locais ou regionais é o que se convencionou chamar de coronelismo eletrônico. Instrumentos de poder e de troca de favores e interesses, as concessões de rádio e televisão têm servido, no Brasil, como moeda de troca entre o governo federal e o setor privado. Entre 1985 e 1988, o então Presidente José Sarney concedeu um grande número de licenças de emissoras de rádio e televisão para empresas ligadas a parlamentares federais, que o ajudaram a aprovar a emenda que lhe deu mandato de cinco anos. Já na era Fernando Henrique Cardoso, até setembro de 1996, foram autorizadas 1848 licenças de RTV (repetidoras de televisão), sendo que 268 para entidades ou empresas controladas por 87 políticos ${ }^{11}$, todos

11 Foram beneficiados diretamente 19 deputados federais, 11 deputados estaduais, 6 senadores, 2 governadores, 7 prefeitos, 3 ex-governadores, 8 ex-deputados federais, 8 ex-prefeitos e 23 outros políticos (Costa e Brener apud BAYMA, 2002). 
favoráveis à emenda da reeleição.

\section{III.2. Cidadania ou instrumentalização das rádios comunitárias nas eleições de 1998 ?}

Na pesquisa realizada sobre a utilização das emissoras comunitárias nas eleições de 1998, foram feitas gravações da programação de três emissoras comunitárias de propriedade de três candidatos: Padre José Linhares ${ }^{12}$, dono da Sal da Terra FM, de Sobral; Gorete Pereira ${ }^{13}$, representada pela rádio Emoção FM, de Fortaleza, e José Arnon Bezerra $^{14}$, representado pela Juazeiro FM, em Juazeiro do Norte.

Os três candidatos, vindos de outros mandatos legislativos, pertencentes a partidos da situação, conseguiram eleger-se com votações expressivas nas eleições de 1998. Gorete Pereira elegeuse Deputada Estadual pelo PFL em nono lugar,

12 O Padre José Linhares Ponte nasceu em 21.out.1930, em Sobral. Assumiu os seguintes mandatos eletivos: Deputado Federal (Congresso Revisor), 1991-1995 (PSDB-CE); Deputado Federal, 1995-1999 (Partido Popular (PP)-CE); Deputado Federal, 1999-2003 (PPB-CE). Suas filiações partidárias foram as seguintes: Partido Democrata-cristão (PDC), 1988-1989; PSDB, 1990-1992; Partido Socialtrabalhista (PST), 1992-1993; PP, 1993-1995; PPB, desde 1995. Suas atividades partidárias foram: Presidente do Diretório Municipal do PSDB em Sobral (1989); Presidente Regional do PP do Ceará (1993); vice-Líder da Bancada do PP (1993-1994); vice-Líder do PPB (1997-1999); Presidente do PPB no Ceará (1997 e 1998); Segundo-Secretário da Comissão Executiva Nacional do PPB (1998). Reeleito Deputado Federal em 1998 pelo PPB, representando o Partido na bancada, José Linhares obteve 94,7\% de freqüência em Plenário durante os trabalhos do ano 2000. De acordo com o jornal Diário do Nordeste de 5.jan.2002, nas comissões, com frequiência média de 75,2\%, Linhares esteve envolvido na Comissão de Direitos Humanos, de Seguridade Social e Família, na Comissão Especial de Elaboração do anteprojeto com vistas à reforma do Regimento Interno da Câmara, da equipe formada para dar parecer ao Estatuto do Idoso e dos projetos de Emenda Constitucional da Cultura e da Discriminação Racial.

13 Maria Gorete Pereira nasceu em 10.abr.1954, em Juazeiro do Norte, e formou-se em Fisioterapia. Gorete exerceu os seguintes cargos eletivos: Vereadora em Fortaleza (1988-1992), pelo PFL, com 3371 votos; Vereadora em Fortaleza (1993-1994), pelo PFL, com 4174 votos; Deputada Estadual (1995-1998), pelo PFL, com 18786 votos; Deputada Estadual (1999-2003), com 28754 votos.

14 José Arnon Cruz Bezerra de Menezes é médico. Foi Deputado Estadual (1991-1995), pelo PFL do Ceará; Deputado Federal (1995-1999), pelo PSDB; Deputado Federal (1999-2003) pelo PSDB. Pertenceu ao PFL entre 1988 e 1993, filiando-se ao PSDB em 1994. Foi Secretário Municipal de Saúde de Juazeiro do Norte (1983-1988). com 28754 votos ou 1,05\% dos votos válidos; Arnon Bezerra reelegeu-se Deputado Federal pelo PSDB, ficando na vigésima-quinta posição, com 66384 votos ou $2,50 \%$ dos votos válidos, e José Linhares também foi reeleito Deputado Federal pelo PPB em nono lugar, obtendo 88129 votos ou $3,32 \%$ dos votos válidos.

Foram gravados os programas das emissoras, no horário das seis às dezoito horas, nos dias $8,9 \mathrm{e}$ 10 de setembro, da Rádio Sal da Terra; dias 7, 9 e 11 de setembro, da Rádio Emoção FM ${ }^{15}$, e 31 de agosto e $1^{\circ}$ e 2 de setembro, da Rádio Juazeiro FM. As emissoras de rádio não foram informadas de que as gravações seriam realizadas ${ }^{16}$.

No material empírico analisado, comprovouse a instrumentalização das rádios comunitárias nas eleições de $1998^{17}$ por meio de propaganda

15 Os dados foram coletados de gravações de programas apresentados em 1998, da rádio comunitária Emoção FM, frequiência 104,9, no bairro da Serrinha, em Fortaleza, que posteriormente foram transcritos e analisados. Os programas gravados foram: Bom dia, emoção, das $6 \mathrm{~h}$ às $9 \mathrm{~h}$ programa Isabelle Fetinhe, das $9 \mathrm{~h}$ às $12 \mathrm{~h}$; Classe $A$, das $12 \mathrm{~h}$ às $14 \mathrm{~h}$; Forrozão da emoção, das $14 \mathrm{~h}$ às $16 \mathrm{~h}$, e Clube do Pimpolho, das $16 \mathrm{~h}$ às $18 \mathrm{~h}$

16 O material gravado foi sistematizado por Ana Cláudia Freitas Pantoja, bolsista de iniciação científica (Conselho Nacional de Pesquisa e Desenvolvimento $(\mathrm{CNPq})$ ) ligada à pesquisa, dando também uma contribuição decisiva na elaboração do relatório da primeira fase da pesquisa.

17 A instrumentalização partidária das rádios comunitárias durante o período eleitoral foi usada como justificativa para desencadear uma ação repressiva sobre todas as rádios, incluindo aquelas comunitárias que não faziam propaganda política para nenhum candidato. Em matéria publicada pelo jornal O Povo, em set.1998, a Procuradoria Regional Eleitoral anunciou a realização de batidas simultâneas nas duas regiões do estado do Ceará com maior concentração de rádios em situação irregular. A operação, em parceira com a Procuradoria da República e Polícia Federal, teria o objetivo de combater o uso político das rádios supostamente comunitárias. A Procuradoria, que não quis divulgar as regiões investigadas, afirmou que a apreensão seria feita independente de as rádios fazerem propaganda eleitoral irregular, como afirmou Gerim Cavalcante, Procurador da República no Ceará e Procurador Eleitoral Auxiliar: "Nós vamos pedir a apreensão dos transmissores. [...] O objetivo é pedagógico". Gerim afirmou que punir as rádios clandestinas pela lei eleitoral seria quase impossível, porque as emissoras não existiam juridicamente. A estratégia seria aplicar a Lei das Telecomunicações, que considera crime o funcionamento de rádios sem autorização do Ministério das Comunicações. "Sendo crime, estamos pedindo a instauração de inquéritos policiais que nos permitem requerer a busca e apreensão dos equipamentos", afirmou Gerim. 
política. O que se entende por instrumentalização eleitoral radiofônica é a utilização da rádio comunitária com propósitos individuais deliberados de caráter político-partidário, comercial ou religioso Essa instrumentalização ocorreu de maneira direta, indireta e subliminar. A participação da comunidade nas programações das rádios restringiu-se a solicitações musicais por meio de telefonemas, não havendo estímulo ao debate das propostas dos candidatos ou sobre temas políticos locais ou nacionais, nem qualquer campanha de conscientização sobre a importância do voto, o que significou uma não contribuição ao efetivo exercício da cidadania por meio da reflexão que poderia ter sido proporcionada por essas emissoras.

Denominamos de instrumentalização direta aquela que apresenta divulgação do nome do candidato ("dono" da rádio) e seus objetivos. Vamos a um exemplo de instrumentalização direta, identificada na rádio Emoção FM, na programação do dia 9.set.1998, em Fortaleza:

Ouvinte: A sua rádio é muito boa.

Locutora: É a rádio da Deputada Gorete Pereira, né?

Ouvinte: $\hat{E}$.

Locutora: É ela quem comanda aqui tudo. A mulher é quente, fervendo.

Ouvinte: Eu sei.

Locutora: Ela faz política. Não faz politicagem

$\mathrm{Na}$ instrumentalização direta, como se pode constatar, o nome da candidata aparece de maneira explícita. No entanto, o aspecto mais grave do exemplo em questão é atribuição da propriedade da rádio à candidata, ao invés de ela ser identificada como pertencendo à comunidade. A proprietária da emissora confunde-se com ela e o caráter comunitário da emissora em nenhum momento é questionado. A comunidade não se identifica na rádio, mas reconhece nela a pessoa da "política" Gorete Pereira. Por que essa emissora representando os interesses comunitários? Ela existe, certamente, para representar os interesses políticos da candidata Gorete Pereira, "credenciada" socialmente para o exercício da cidadania e da vivência plena dos seus direitos democráticos, ao contrário dos ouvintes desprovidos de toda e qualquer possibilidade de manifestação de seus anseios e direitos, no espaço da rádio comunitária que era público, mas que foi apropriado pelo privado.

Outra forma de instrumentalização identificada foi a indireta, que consistiria na divulgação das obras realizadas pelos candidatos, principalmente obras de mandatos anteriores. Essa forma de instrumentalização é aparentemente casual e descompromissada. Observe-se este exemplo veiculado na Rádio Sal da Terra Fm ${ }^{18}$, em 8.set.1998, em Sobral:

Locutor: Você sabia? A Santa Casa de Misericórdia de Sobral mantém um dos melhores hotéis da Zona Norte, o Visconde Hotel. Com restaurante aberto ao público $24 \mathrm{~h}$, sala de reuniões, transporte para city-tour. O único com apart-hotel. Visconde Hotel, atendimento de primeira classe.

Nesses exemplos há referências explícitas a obras do candidato Padre José Linhares, realizadas durante um de seus mandatos. Tanto a Santa Casa de Misericórdia quanto o hotel foram realizações suas. Após semanas de propaganda intensiva sobre as vantagens do Hotel Visconde (devidamente acompanhadas de mensagens sobre as obras por meio das quais as pessoas revelamse), o que aconteceria quando o ouvinte ouvisse falar que foi o padre José Linhares o responsável pelo hotel?

A mais significativa forma de instrumentalização das rádios, a subliminar, não se dá tanto por interesses econômicos e político-partidários. Ela ocorre, na maior parte das vezes, por desconhecimento do papel das emissoras junto à comunidade. Os locutores e produtores, em sua maioria, não têm noção do potencial aglutinador e mobilizador das rádios comunitárias.

Na emissora Juazeiro FM 102,5, pertencente à Fundação Leandro Bezerra ${ }^{19}$, patriarca da família Bezerra, o candidato à reeleição era o Deputado Federal José Arnon Bezerra e a instrumentalização política foi feita de maneira direta, sem nenhuma preocupação em disfarçar-se. Com uma programação predominantemente musical, com

18 Em maio.2002 a emissora encontrava-se fechada pela ANATEL. As mensagens abaixo foram repetidas inúmeras vezes ao longo da programação da emissora.

19 Leandro Bezerra é o pai de José Arnon Bezerra. 
programas que veiculavam os diversos estilos musicais (reggae, música popular brasileira, disco music, forró, axé etc.), as referências à campanha eleitoral de José Arnon eram explícitas.

Em um santinho da campanha de Arnon, de n. 4 541, há, no verso, uma mensagem denominada Pegadas na areia, cujo conteúdo é a descrição da atitude de Jesus, que "carrega" seus filhos nos braços e acompanha-os nos momentos mais difíceis e angustiosos da vida. A mensagem sugere proteção, paternalismo. Associá-la às práticas clientelistas, à troca de favores e ao cumprimento de promessas e da palavra empenhada é o caminho natural. A ilação mais simples é que, assim como Jesus, Arnon está e estará ao lado de seus correligionários e eleitores nos momentos mais difíceis.

Nas eleições de 1998, especificamente, acompanhando o desempenho dos candidatos que usaram rádios comunitárias (utilizadas por eles como uma outra estratégia de marketing eleitoral em suas campanhas), identificamos uma completa distorção do sentido comunitário dessas emissoras, revestidas com um discurso profundamente unilateral e, portanto, autoritário, impossibilitando o exercício de uma cidadania vivenciada por meio do acesso a um meio de comunicação alternativo que pudesse não só refletir os interesses de comunidades localizadas, mas ajudar no processo de consolidação da identidade comunitária, como lembra Canclini (1997), quando frisa que os avanços tecnológicos midiáticos passaram a ser utilizados pelos índios mexicanos no fortalecimento de sua própria identidade.

IV. ELEIÇÕES 2000: RÁDIOS COMUNITÁRIAS COMOINSTRUMENTOS ELEITORAIS ${ }^{20}$

IV.1. FM Portugal: rádio "comunitária" "caçaníquel"

A segunda fase da pesquisa, nos anos 2000-

20 Conforme dados do Tribunal Superior Eleitoral, há no Brasil 8,5 milhões de eleitores analfabetos, outros 24,8 milhões que apenas sabem ler e escrever e 37,1 milhões que não completaram o $1^{\circ}$ grau. Esse contingente vai às urnas "para conduzir representantes que quase nunca têm a ver com a sua realidade e seu mundo material", denuncia a Professora do Departamento de Ciência Política da Universidade de Brasília (UnB), Lúcia Avelar. Do total de 33 milhões de analfabetos, $47 \%$ encontram-se nos estados do Norte e Nordeste. "Com a ancestralidade oligárquica da política brasileira, não é difícil concluir quem influencia o seu voto", sintetiza Avelar (apud BAYMA, 2002).
2001, ocorreu de modo similar, com gravação e posterior transcrição da programação integral de duas rádios comunitárias: Portugal FM e Mandacaru FM, ambas em Fortaleza.

No caso da FM Portugal 97,7, emissora ligada à Associação dos Moradores do Parque Araxá, situada na rua professor Anacleto, 392-C, na Parquelândia, pôde-se observar a utilização da rádio denominada de "comunitária" apenas como forma de angariar a simpatia do público e auferir recursos financeiros. Apesar de vinculada ao candidato a Vereador de Fortaleza, pela coligação Partido Popular Socialista (PPS)-PSDB, Gilmar Gondim Bezerra Lima Filho ${ }^{21}$, nas eleições 2000 a emissora ${ }^{22}$ não foi utilizada durante a campanha eleitoral. $\mathrm{Na}$ programação, predominantemente musical, não foram identificadas formas diretas ou indiretas de propaganda de quaisquer candidatos.

IV.2. Mandacaru FM: um exemplo do exercício da cidadania

A Rádio Mandacaru 98,5 FM²3, ligada à Associação dos Moradores do Bairro Ellery, abordou o tema "eleições" de um modo completamente diferente das demais emissoras. Situada em um bairro operário, a população formada por trabalhadores, sindicalistas e militantes de partidos de esquerda sempre teve uma tradição histórica nas lutas populares e no processo de organização popular. A rádio, que surgiu inicialmente com um sistema de alto-falantes, é uma emissora comunitária, contando com gestão participativa, representação plural da população em sua programação, que é totalmente elaborada pela comunidade ${ }^{24}$. Apesar de muitos de seus militan-

\footnotetext{
21 Gilmar ficou em $40^{\circ}$ lugar, obtendo 1113 votos.

22 Em maio.2002 a emissora encontrava-se funcionando, por meio de liminar.

23 Em maio.2002 a emissora encontrava-se funcionando, por meio de liminar.

24 Durante a programação são divulgados inúmeras campanhas educativas: contra a aids e doenças sexualmente transmissíveis, feitas pelos Radialistas contra a Aids e pelo Instituto de Saúde e Desenvolvimento Social; campanhas contra o maltrato de velhos, a agressão a crianças e a favor do exame pré-natal das gestantes, de iniciativa do Pacto Comunitário contra a Violência Familiar, Sociedade Civil organizada, Ministério da Justiça e Organização das Nações Unidas. Há uma forte preocupação, na programação, com a transmissão de noções básicas de saúde e educação, além de informações úteis para a vida prática.
} 
tes serem ligados a partidos de esquerda, especialmente o Partido Comunista do Brasil (PCdoB), em nenhum momento ouviu-se qualquer referência a questões partidárias ou ao candidato do PCdoB à Prefeitura de Fortaleza nas eleições de 2000, Inácio Arruda.

$\mathrm{Na}$ análise do material empírico da Rádio Mandacaru 98,5 FM, pôde-se identificar uma emissora comunitária ajudando a comunidade a exercer sua cidadania durante o processo eleitoral. Uma ampla campanha de conscientização da importância do voto, da participação política, da relação entre eleições e exercício da cidadania, foi desencadeada pela rádio. A análise da programação dos três dias que antecederam as eleições demonstra uma preocupação articulada de todos os participantes da rádio, já que, em todos os programas, os apresentadores insistiram na mesma argumentação.

Um jingle, produzido pelo Fundo da Organização das Nações Unidas para a Infância (UNICEF) e cantado por jovens em ritmo de rap - a Campanha do Selo - Município Aprovado - foi veiculado insistentemente antes ou após a fala do apresentador: "Não. Não. Não vote em vão. Vote consciente. Seja cidadão. Não. Não. Não vote em vão. Vote consciente. Seja cidadão. Voto é coisa séria. Não é brincadeira. Então faça a sua parte. Não fique de bobeira. Dê um ponto final na corrupção. Chega de votar em quem mete a mão. Juventude de atitude não se ilude e vota certo. Vote pra eleger um candidato honesto. Não. Não. Não vote em vão. Vote consciente. Seja cidadão".

A programação da rádio, extremamente plural, alertou, sistematicamente, o ouvinte sobre o papel do voto na vida do cidadão. No programa "Cidadão no rádio", apresentado por Josimar Marques e Eudes Batista, no dia 28.set.2000, falou-se de eleições em várias ocasiões. Em certo trecho, o apresentador revelou que, segundo as pesquisas, a maioria dos brasileiros ainda não sabia em quem votar e apelou: "Vamos votar consciente, porque o voto são quatro anos de muita responsabilidade. O voto é uma coisa muita séria".

No programa "Nas ondas do reggae", apresentado das $17 \mathrm{~h}$ às $18 \mathrm{~h}$, por Galego Jones e Eunice, "a dama do reggae", um dos programas mais ouvidos da emissora, o apresentador Galego Jones chamou a atenção dos ouvintes: "Pense bem na hora que você for votar. Não veja a boniteza, mas, sim, pelo que vai fazer para a sua cidade".

Uma das principais conseqüências da modificação do processo de produção dos programas radiofônicos - que em muitos casos é coletivo - é o impacto na recepção. Os produtos radiofônicos elaborados por meio da deglutição do maciço sob a ótica popular, como bem focalizou Oliveira (2002), são fruto da interação entre as raízes e as referências culturais de uma comunidade e o maciço. Ao contrário da indústria cultural - que, muitas vezes, reconfigura as manifestações culturais com fins exclusivamente consumistas -, essa fusão entre o popular e o maciço resulta em uma recriação original das manifestações culturais de acordo com as experiências concretas e o referencial histórico político e cultural de cada comunidade.

Ao analisar formas diferenciadas de recepção dos produtos radiofônicos de rádios autenticamente comunitárias, identificamos o ápice na recepção coletiva nos grupos culturais de determinados programas. Os laços da comunidade estreitam-se e a consciência política e o poder de organização ampliam-se, consolidando o exercício da cidadania. Quando os jovens reúnem-se para escutar determinado programa, como acontece na Mandacaru FM (idem), o fim não é exclusivamente o consumo, mas identificar e unir, de modo solidário, os militantes de um movimento cultural no interior de uma comunidade. Essa visão simbólica, virtual, é um momento decisivo de afirmação cultural, assumindo uma dimensão política e social que aponta para a importância das vivências coletivas, no interior da sociedade, como prática capaz de fortalecer a auto-estima social, gerando avanços nos processos de organização política e social e na direção do exercício de uma cidadania comprometida com as causas coletivas.

\section{V.CONCLUSÕES}

Neste momento, em que vivemos a redefinição da esfera pública social, cujas relações não são mais mediadas pelo discurso e pela racionalidade dos argumentos de seus participantes, mas sim por meio da mídia, as experiências no campo da comunicação comunitária assumem excepcional importância para a interlocução dos diferentes sujeitos sociais e, sobretudo, para os protagonistas dos movimentos sociais.

Em um país com elevado grau de analfabetismo como o Brasil, as rádios comunitárias teriam um 
importante papel, não determinando, mas influenciando a formação do senso crítico, estimulando a reflexão.

Todavia, o exercício da cidadania por meio da participação da comunidade na rádio comunitária é hoje extremamente prejudicado pela instrumentalização eleitoral e comercial progressiva existente na maioria das emissoras denominadas de "comunitárias".

Não é possível a consolidação da identidade comunitária por meio dessas emissoras, porque elas representam interesses privados específicos. Apropriando-se do espaço público, os políticos profissionais privatizam a cena pública e dissolvem a cena pública midiática, que se poderia constituir no livre espaço do debate democrático, para exaltar suas qualidades públicas, suas realizações, ao fazer campanha eleitoral de maneira direta, indireta ou subliminar.

O incipiente da organização da maior parte dessas comunidades revela-se também no despreparo de produtores e locutores que são representantes da própria comunidade, incapazes de exercer sua cidadania, estimulando formas de interação coletiva restrita aos programas de seleção musical, sem utilizar a crítica, o debate ou o questionamento.

As rádios comunitárias podem converter-se em um poderoso instrumento da educação não formal como caminho para o exercício de uma cidadania consciente, reafirmando práticas culturais coletivas responsáveis pela consolidação de uma identidade cultural determinada. Esse sentido "positivo", "afirmativo", por meio do qual a rádio comunitária é forjada pela comunidade, dá bem a dimensão do processo de construção coletiva e de gestão compartilhada da rádio comunitária que representa os interesses plurais de uma comunidade.

A utilização da rádio comunitária em prol dos interesses coletivos, com o engajamento da comunidade, como é o caso da Rádio Mandacaru $\mathrm{FM}$, em que as pessoas percebem a rádio como um produto da construção coletiva, amplia o grau de consciência política e social, permitindo o efetivo exercício da cidadania por meio da participação popular ativa nos processos eleitorais e não como mero instrumento de marketing, como costuma ocorrer no fenômeno da instrumentalização eleitoral das rádios comunitárias, como ficou constatado nas emissoras Sal da Terra FM, Juazeiro FM e Emoção FM.

Ao invés de fundir as manifestações culturais, apagando as diferenças e ressaltando só os pontos comuns, as rádios comunitárias verdadeiramente comprometidas com as causas coletivas, por meio de sua programação, procuram evidenciar a pluralidade de manifestações culturais de grupos e indivíduos na projeção de uma segmentação que é sempre resultado da ampla participação popular. Se a mídia convencional muitas vezes induz comportamentos passivos, a rádio comunitária, com sua proposta de produção coletiva da programação e de gestão compartilhada e representação da pluralidade e da diversidade culturais, abre-se receptiva às diferenças e incentiva o exercício da cidadania e da participação social.

Além disso, a prática da cidadania por meio dos processos participativos comunitários não transfere à mídia o papel de cobrar das autoridades competentes a resolução dos problemas comunitários. A mídia e a comunidade fundem-se em uma só estrutura, traduzindo a nova face da esfera pública social contemporânea, em que se fortalece a rádio comunitária, que se confronta, abertamente, com os poderes constituídos, exigindo o atendimento de suas reivindicações e o respeito aos direitos coletivos essenciais. Essa vivência cidadã por meio da participação coletiva na construção de uma mídia própria, além de fortalecer os laços de solidariedade na comunidade, combate as práticas de mistificação de comunicadores, transformados em "delegados do ouvinte", contribuindo para reduzir a influência dos grandes conglomerados de comunicação e consolida essa nova esfera pública social midiatizada.

Márcia Vidal Nunes (marciavi@ ufc.br) é Doutora em Sociologia pela Universidade Federal do Ceará (UFC) e Professora do Departamento de Comunicação Social da mesma instituição. 


\section{REFERÊNCIASBIBLIOGRÁFICAS}

ACIOLI, S. 2002. Fundação Casa Grande : comunicação para a educação. Fortaleza. Monografia (Graduação em Comunicação Social). Universidade Federal do Ceará.

AGUILAR, M. Á. (org.). 1999. Medios de comunicación y cultura política. Madrid : P. Iglesias.

BARBALET, J. M. 1989. A cidadania. Lisboa : Estampa.

BAYMA, I. F. C. 2002. Dados sobre a concentração da propriedade dos meios de comunicação e o coronelismo eletrônico no Brasil. Disponível em : http://www.eptic.com.br. Acesso em : 21.maio.2002.

BREGUÊS, S. G. 2001. Favela FM 104,5 : uma experiência de rádio comunitária em Belo Horizonte. Sala de Prensa, Ciudad de México, año III, v. 2, feb. Disponível em : http:// www.saladeprensa.org/art200.htm. Acesso em :16.jun.2004

CANCLINI, N. G. 1997. Consumidores e cidadãos - conflitos multiculturais da globalização. Rio de Janeiro : UFRJ.

CASTRO, D. 2000. Políticos controlam 2000 rádios piratas. Folha de S. Paulo, 26.jun., p. A6.

COGO, D. M. 1998. No ar... uma rádio comunitária. São Paulo : Paulinas.

FERNÁNDEZ, A. J.P. 1998. Democratização do ar como exercício de cidadania. São Paulo. Dissertação (Mestrado em Ciências da Comunicação). Universidade de São Paulo.

FERREIRA, M. N. (org.). 1999. Cultura, comunicação e movimentos sociais. São Paulo : USP.

FESTA, R. \& SILVA, C. E. L. (orgs). 1986. Comunicação popular e alternativa no Brasil. São Paulo : Paulinas.

GOMES, W. 1998. Esfera pública, política e media : com Habermas, contra Habermas. In : RUBIM, A. A.C., BENTZ, I. M. G. \& PINTO, M. J. (orgs.). Produção e recepção dos sentidos midiáticos. Petrópolis : Vozes.

GUATARI, F. 1981. Revolução molecular : pulsações políticas do desejo. $2^{\mathrm{a}}$ ed. São Paulo: Brasiliense.
LIMA, V. A. 2001. Mídia - teoria e política. São Paulo : Fundação Perseu Abramo.

MENDONÇA, D. 2001. Casos e coisas. São Paulo : Globo.

MONTORO, T. S. 1997. Comunicação, cultura, cidadania e mobilização social. Brasília : UNB.

MONZÓN, C. 1996. Opinión pública, comunicación y política. La formación del espacio público. Madrid : Tecnos.

NAHRA, C. M. L. 1988. Rádio institucional e rádio livre: rupturas no modelo comunica-cional dominante. Florianópolis. Dissertação (Mestrado em Sociologia Política). Universidade Federal de Santa Catarina.

NUNES, M. V. 2000. Rádio e política. Do microfone ao palanque - os radialistas políticos em Fortaleza (1982-1996). São Paulo : Annablume.

2001. Rádios comunitárias no século XXI : exercício da cidadania ou instrumentalização. In : MOREIRA, S. V. \& BIANCO, N. R. B. (orgs.). Desafios do rádio no século XXI. Rio de Janeiro : UERJ.

2002. Mídia e eleições : o rádio como arma política. Comunicação \& Política, Rio de Janeiro, v. IX, n. 1, p. 196-228, jan.-abr.

NUNES, M. V. \& MATOS, H. 2003. Marta "faz" marca e Maluf "faz" : estratégias de marketing político nas eleições municipais em São Paulo, em 2000. In : CARVALHO, R. V. A. (org.). A produção da política em campanhas eleitorais. Campinas : Pontes.

NUNES, M. A. M. 1995. Rádios livres - o outro lado da voz do Brasil. São Paulo. Dissertação (Mestrado em Ciências da Comunicação). Universidade de São Paulo.

OLIVEIRA, C. T. F. 2002. Escuta sonora : educação não-formal, recepção e cultura popular nas ondas das rádios comunitárias. Campinas. Tese (Doutorado em Educação). Universidade Estadual de Campinas.

OLIVEIRA, V.C. 2000. A reconfiguração do espaço público nas ondas das rádios comunitárias. Anais do I Simpósio de Rádio e Cidadania na América Latina. São Paulo : digit. 
PERUZZO, C. M. K. 1998. Comunicação nos movimentos populares. A participação na construção da cidadania. Petrópolis : Vozes.

RUBIM, A. A. C. 1999. Mídia e política no Brasil. João Pessoa : UFPB.

(org.). 2000. Mídia e eleições de 1998 Salvador: UFBA.
SPENILLO, G. 2001. Comunicação comunitária e novas tecnologias. Por uma formação profissional em busca da cidadania. Anais do XXIV Congresso Brasileiro da Comunicação. Campo Grande : Sociedade Brasileira de Estudos Interdisciplinares da Comunicação.

\section{OUTRASFONTES}

No Ceará, 40 rádios foram autorizadas em 19 meses. 2002. O Povo, Fortaleza, 26.jan., p. 8.
Tem Cabral no seu dial. 1987. Veja, S. Paulo, 17.set., p. 103. 